\title{
Analysis of biologic therapy in rheumatoid arthritis in a southern Spanish hospital population
}

\author{
J Uceda-Montañés*, R Hernández-Sánchez, S Rodríguez-Montero, M L Velloso-Feijoo, A Muñoz-Jimenez, \\ R Martínez-Perez, J L Marenco
}

From 5th European Workshop on Immune-Mediated Inflammatory Diseases

Sitges-Barcelona, Spain. 1-3 December 2010

\section{Objectives}

To analyze RA patients treated with biologics in a University Hospital. Proportion of patients treated with different drugs, as first, second or third choice. To know the disease activity before and after biologic therapy. To know side effects and the reasons.

\section{Material and methods}

We have reviewed all RA patients treated with biologicals from 1998 to January 2010. We include all patients with at least 6 months of follow up and analyze clinical efficacy as improvement in DAS count. We registered the cause for switch among biologic drugs and the response to a new biologic. Our hospital attends about 350.000 inhabitants and the prevalence of RA in Spain, as settled by Spanish Society for Rheumatology is $0.5 \%$, so we could expect to have about 1800 RA patients, so we are treating about $12 \%$ of RA patients with biologicals.

\section{Results}

We have reviewed 206 patients, $68 \%$ female, mean age 56.5 , average duration of the disease 10.8 years. RF positive $79.3 \%$ CCP $68.2 \%$, erosive $58.2 \%$. Initial DAS was 5.8 and at the end evaluation $53,6 \%$ of patients have a DAS $<2.6$.

Etanercept was the most used at onset (58\%), 76 patients (36.4\%) switched for inefficacy (62\%) or side effects (21.7\%).

Side effects were registered in $39 \%$, with drug stop in $81 \%$ and hospital admission in $18.9 \%$. The more common side effects were reactions at the injection site $33 \%$, infectious processes $23.1 \%$ and skin alterations $17.9 \%$.

\section{Conclusions}

The disease activity was high when biologic started, (DAS 5.8). The main cause of switching is loss of efficacy. Etanercept is the more prescribed drug to initiate biologic therapy.

Rituximab and Etanercept are used as a second option in the majority of patients. Abatacept is used only after a second switch. The improvement of patients is notorious with RA remission by DAS $<2.6$ in $53,6 \%$ of patients. The frequency of switch biologics is similar to other registry experiences.

Published: 25 November 2010

doi:10.1186/1479-5876-8-S1-P72

Cite this article as: Uceda-Montañés et al:: Analysis of biologic therapy

in rheumatoid arthritis in a southern Spanish hospital population.

Journal of Translational Medicine 2010 8(Suppl 1):P72.

Rheumatology Unit, Valme University Hospital, Seville, Spain 